\title{
RP-HPLC Method for Determination of Organophosphate and Synthetic Pyrethroids Insecticides
}

\author{
Romila Akoijam $^{1 *}$, Arati Ningombam ${ }^{1}$, Aruna Beemrote ${ }^{1}$ and R.S. Telem ${ }^{2}$ \\ ${ }^{1}$ ICAR Research Complex for North Eastern Hill Region, Manipur Centre, Lamphelpat, India \\ ${ }^{2}$ Farm Science Centre (KVK), Hengbung, Senapati, India \\ *Corresponding author
}

\begin{tabular}{|l|}
\hline K e y w o r d s \\
Monocrotophos, \\
$\begin{array}{l}\text { Deltamethrin, Cabbage, } \\
\text { Cauliflower, HPLC }\end{array}$ \\
\hline Article Info \\
\hline $\begin{array}{l}\text { Accepted: } \\
22 \text { October } 2018 \\
\text { Available Online: } \\
10 \text { November } 2018\end{array}$ \\
\hline
\end{tabular}

\section{Introduction}

The cole crops usually thrive best on cool climate. They are grown in the plains during the winter season whereas in hilly regions, it can be grown throughout the year. In India, cabbage and cauliflower were the only cole crops among Brassica vegetables, grown on commercial scale (Chatterjee, 1986). In North eastern states like Manipur, the cole crops are grown almost throughout the year and add a good contributor in the economy of vegetable growers. The sub-tropical monsoon type of climate found in Manipur has four different seasons namely the cold or winter season, the hot-dry season or spring-summer, the rainy season, and the retreating monsoon season.

The state has an ambient temperature which is generally varies from a minimum range of 3.5 to $21^{\circ} \mathrm{C}$ and maximum of 22 to $32^{\circ} \mathrm{C}$ with the relative humidity ranging between 48 and $82 \%$. The state receives south-west monsoon in an annual rainfall of approximately 1436 $\mathrm{mm}$ in the plains. The agricultural economy of the country is contributed by the growing of different types of vegetable crops. To get the higher yields in different parts of the country, 
adoption of modern agricultural practices like use of high yielding varieties, heavy manuring and proper irrigation were practiced. Being succulent, the problems of insect pests attacking at different stages of crop growth are very high (Sachan and Gangwar, 1980). A total of 51 insect pests have been reported to attack on cruficers (Lal, 1975). Among the insect pests, cabbage butterfly, diamond back moth, cabbage aphid are the most persistent in Meghalaya, Manipur, Mizoram and Sikkim. Different types of pesticides are using for increasing the crop production in north eastern states. The Manipur state consumed pesticide at the rate of 26.2 metric tones per acre in the year 2012 (Envis, 2015). At the same time, there is a rising public concern about the potential adverse effects of chemical pesticides on the human health, environment and biodiversity. Use of pesticide in crop production is a common incident, regular monitoring of residues levels of pesticides in food commodities is of vital importance to human being. The presence of residues of organochlorine, organophosphorus and synthetic pyrethroid insecticides on market samples of brinjal were found in Manipur (Singh et al., 2010). The moderately toxic insecticides like cypermethrin, imidacloprid, profenofos, chlorpyrifos, propineb, dichlorvos were used in tomato crops (Shovarani et al., 2015). It is well known that the pesticide application in crops represents a possible risk for the environment, farmers and consumers. Knowing the level of pesticides residues in vegetable crops especially cole crops is very essential as cabbage and cauliflower may consumed directly without much processing. There are no informations available on the nature and quantity of pharmacologically active compounds of different insecticides in cabbage and cauliflower which is necessary to ensure the safety of the consumers and the environment. Therefore, the method was developed for the simultaneous estimation of monocrotophos, deltamethrin, phosphamidon and dichlorovos insecticides in cabbage and cauliflower.

\section{Materials and Methods}

The experiment was conducted at Indian Council of Agricultural Research-Research Complex for North Eastern Hill region Manipur Centre, Lamphelpat, India.

The technical grade analytical standards such as monocrotophos (99.8\%), deltamethrin (99.90\%), phosphamidon $(94.80 \%)$ and dichlorovos $(99.80 \%)$ and primary secondary amine (PSA) sorbent were procured from sigma-aldrich, Kolkatta (Fig. 1). Chemicals such as sodium chloride, activated anhydrous magnesium sulphate $\left(\mathrm{MgSO}_{4}\right)$, anhydrous sodium sulfate and solvents like highperformance liquid chromatography (HPLC) grade acetonitrile, HPLC grade water were obtained from E. Merck (India) Ltd, Mumbai, India. All the solvents used were of laboratory grade and were redistilled in all glass apparatuses before experiment. The suitability of the solvents and other chemicals was ensured by running reagent blanks before sample analysis.

The high-performance liquid chromatograph (series 200) was equipped with a reversephase, RP, C18 column and a UV-VIS detector, and dual pumps supplied by M/S Perkin Elmer, United States. The HPLC column, a Brownlee Analytical C18 column (150 $\mathrm{mm}$ column length, $4.6 \mathrm{~mm}$ inside diameter and $5 \mu \mathrm{m}$ particle size) was also procured from M/S Perkin Elmer. For the control of instrument, data acquisition and processing, TC Nav software was used. A good satisfactory separation of peak symmetry was obtained with an isocratic mobile phase comprising of acetonitrile: water (90: 10, v/v) at a flow rate of $1.70 \mathrm{~mL} / \mathrm{min}$ for method 1 . In this, quantification of monocrotophos and deltamethrin was done with UV-VIS detection 
at $225 \mathrm{~nm}$ based on peak area with a retention factor of $10 \mathrm{~min}$ and injection volume of 20 $\mu \mathrm{L}$. Another method 2, the quantification of phosphamidon and dichlorvos was achieved with an isocratic mobile phase comprising of acetonitrile : water $(70: 30, \mathrm{v} / \mathrm{v})$ at a flow rate of $1.50 \mathrm{~mL} / \mathrm{min}$ with UV-VIS detection at 210 $\mathrm{nm}$ wavelength based on peak area with a retention factor of $10 \mathrm{~min}$ and injection volume of $20 \mu \mathrm{L}$.

A standard stock solution of monocrotophos, deltamethrin, phosphamidon and dichlorvos (1 $\mathrm{mg} / \mathrm{mL}$ ) was prepared in HPLC grade acetonitrile. For the construction of a calibration curve, the standard solutions 2.00 to $20.00 \mathrm{mg} / \mathrm{mL}$ required were prepared from stock solution by serial dilution with HPLC grade acetonitrile. Prior to experiment, all the standard solutions were stored at $4^{\circ} \mathrm{C}$.

Cabbage and cauliflower samples were used as substrates for standardization of the methodology proposed for estimation of monocrotophos, deltamethrin, phosphamidon and dichlorvos insecticides. Cabbage and cauliflower treated to be control samples were collected a known source where there is no history of pesticides application. The cabbage and cauliflower samples were fortified at different levels, i.e., 0.05, 0.10, 0.25, 0.50 and $1.00 \mathrm{mg} / \mathrm{kg}$. There were five replications for each treatment of both the samples.

The quick easy cheap effective rugged and safe (QuEChERS) method was modified by taking a representative sample of $15 \mathrm{~g}$ each of blended cabbage and cauliflower samples were weighed separately into $50 \mathrm{~mL}$ centrifuge tube. After that $30 \mathrm{~mL}$ of acetonitrile was poured into all the centrifuge tubes. The samples were vigorously shaken. Sodium chloride (10 g) was added to each sample and shaken dynamically by rotospin for around $5 \mathrm{~min}$. The samples were centrifuged using a laboratory REMI centrifuge for $3 \mathrm{~min}$ at $6000 \mathrm{rpm}$. The top 15 $\mathrm{mL}$ organic layer from each of the $15 \mathrm{~mL}$ tube was decanted into another $50 \mathrm{~mL}$ centrifuge tube which was weighed with $10 \mathrm{~g}$ of activated sodium sulfate. It was again shaken using a rotospin for $2 \mathrm{~min}$. The sample extract (6 mL) was transferred to a $15 \mathrm{~mL}$ centrifuge tube containing PSA sorbent $(150 \mathrm{mg})$ and activated anhydrous magnesium sulfate (900 $\mathrm{mg}$ ). The tube was tightly capped and vortexed for $30 \mathrm{~s}$. The tubes were centrifuged for $3 \mathrm{~min}$ at $3000 \mathrm{rpm}$. The top extract $(4 \mathrm{~mL})$ was transferred into a test tube and concentrated to $2 \mathrm{~mL}$ with a rotary evaporator under $35^{\circ} \mathrm{C}$ for further quantification by HPLC.

\section{Results and Discussion}

Reversed-phase HPLC equipped with UV-VIS detector, was shown to be good for determination of monocrotophos, deltamethrin, phosphamidon and dichlorvos because no need for derivatization step. Chromatographic separation in Brownlee analytical C18 columns provides good result. The detection at $225 \mathrm{~nm}$ and $210 \mathrm{~nm}$ provides suitable chromatograms for the method 1 i.e. monocrotophos and deltamethrin and method 2 i.e. phosphamidon and dichlorvos in real samples. Under the preferred conditions monocrotophos and deltamethrin showed retention times at $0.76 \mathrm{~min}$ and $2.85 \mathrm{~min}$ and the peaks of phosphamidon and dichlorovos was found at $1.10 \mathrm{~min}$ and $1.37 \mathrm{mins}$ of retention factor (Fig. 2).

The recovery percentage of spiked samples of cabbage at different levels were found to be in the range of 82.28 to $97.75 \%$ for monocrotophos, 85.15 to $93.16 \%$ for deltamethrin, 80.38 to $95.38 \%$ for phosphamidon and 83.23 to $98.26 \%$ for dichlorvos (Table 1). Similarly, in spiked samples of cauliflower, the recovery ranges were all above $80 \%$ in all the levels (Table 2). 
Fig.1 Chemical structure of (a) monocrotophos (b) deltamethrin (c) phosphamidon and (d) dichlorvos<smiles>CNC(=O)/C=C(\C)OP(=O)(OC)OC</smiles>

(a) Monocrotophos<smiles>CCN(CC)C(=O)/C(Cl)=C(\C)OP(C)(=O)OC</smiles>

(c) Phosphamidon<smiles>N#CC(OC(=O)C1C(C=C(Br)Br)C1CBr)c1cccc(Oc2ccccc2)c1</smiles>

(b) Deltamethrin<smiles>COP(=O)(OC)OC=C(Cl)Cl</smiles>

(d) Dichlorvos

Fig.2 HPLC chromatograms of standards of monocrotophos and deltamethrin in which retention times on $\mathrm{x}$-axis and \% deflection on $\mathrm{y}$-axis

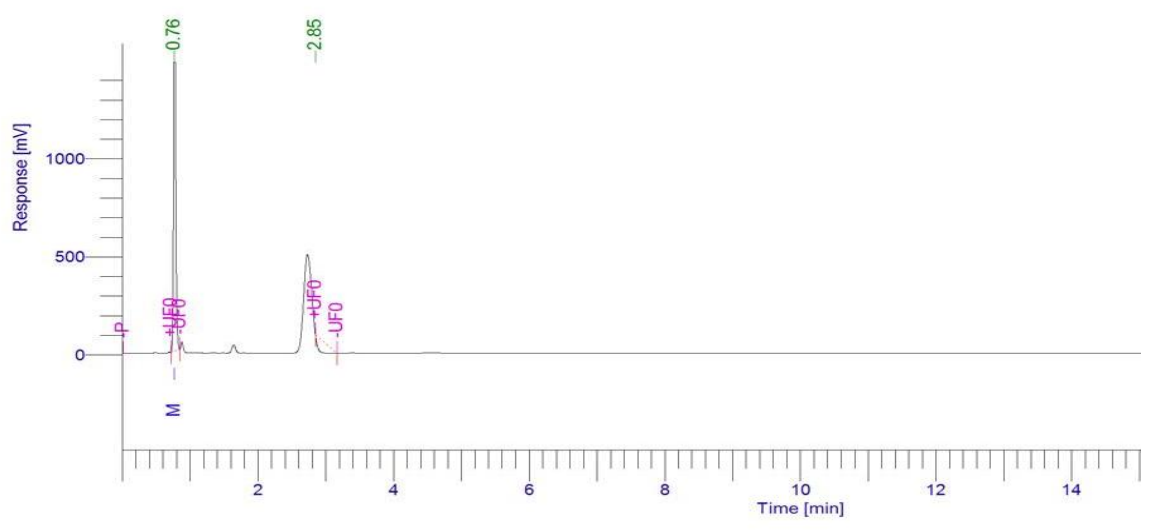

Fig.3 HPLC chromatograms of standards of phosphamidon and dichlorvos in which retention times on $\mathrm{x}$-axis and \% deflection on $\mathrm{y}$-axis

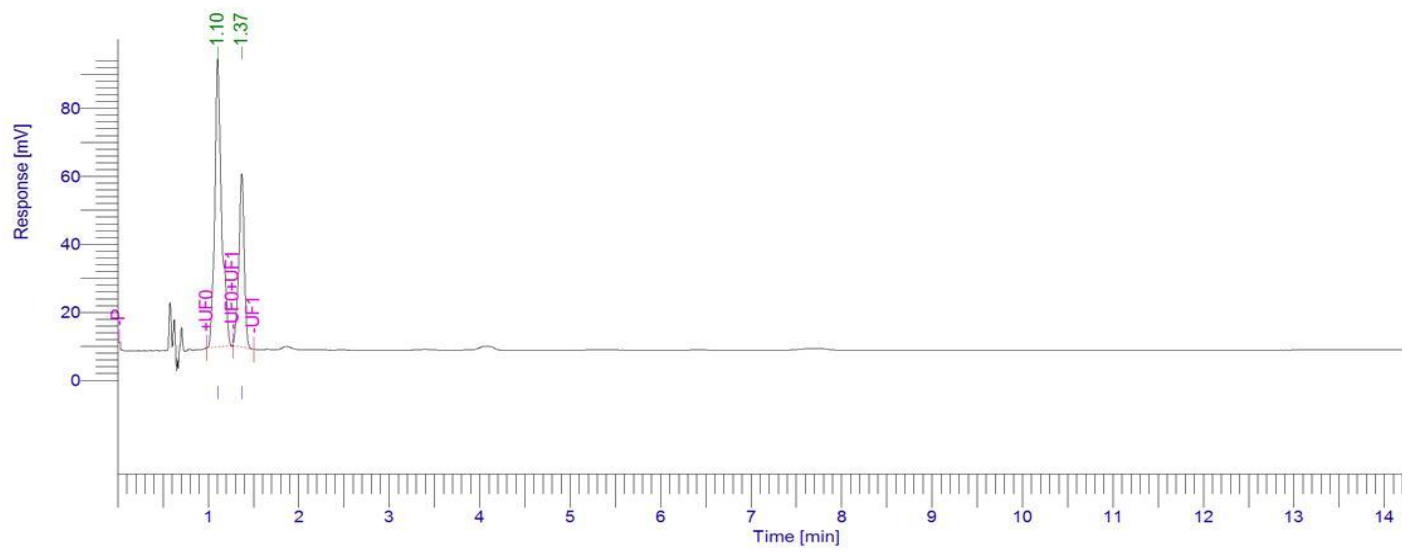


Table.1 Recovery (\%) of monocrotophos, deltamethrin, phosphamidon and dichlorvos in cabbage $(n=5)$

\begin{tabular}{|l|l|l|l|l|}
\hline $\begin{array}{l}\text { Level of } \\
\text { fortification } \\
\left(\mathbf{m g ~ k g} \mathbf{~ k g}^{-1}\right)\end{array}$ & $\begin{array}{l}\text { Monocrotophos } \\
\text { deltamethrin }\end{array}$ & phosphamidon & Dichlorvos \\
\hline $\mathbf{0 . 0 5}$ & $82.28 \pm 2.98$ & $86.28 \pm 0.97$ & $87.56 \pm 2.90$ & $98.26 \pm 1.78$ \\
\hline $\mathbf{0 . 1 0}$ & $94.40 \pm 1.29$ & $85.15 \pm 1.76$ & $95.38 \pm 3.02$ & $86.60 \pm 0.65$ \\
\hline $\mathbf{0 . 2 5}$ & $84.13 \pm 0.36$ & $90.28 \pm 1.08$ & $83.20 \pm 1.90$ & $83.23 \pm 1.45$ \\
\hline $\mathbf{0 . 5 0}$ & $88.27 \pm 0.27$ & $87.78 \pm 3.00$ & $80.38 \pm 2.05$ & $91.79 \pm 0.65$ \\
\hline $\mathbf{1 . 0 0}$ & $97.75 \pm 1.04$ & $93.16 \pm 2.87$ & $92.37 \pm 0.69$ & $90.65 \pm 0.65$ \\
\hline
\end{tabular}

${ }^{\mathrm{a}}$ Mean \pm Standard deviation

Table.2 Recovery (\%) of monocrotophos, deltamethrin, phosphamidon and dichlorvos in cauliflower $(n=5)$

\begin{tabular}{|l|l|l|l|l|}
\hline $\begin{array}{l}\text { Level of } \\
\text { fortification } \\
\left(\mathbf{m g ~ k g} \mathbf{~ k}^{-1}\right.\end{array}$ & Monocrotophos & deltamethrin & phosphamidon & Dichlorvos \\
\hline $\mathbf{0 . 0 5}$ & $90.45 \pm 2.09$ & $85.38 \pm 1.20$ & $86.20 \pm 3.18$ & $92.12 \pm 0.97$ \\
\hline $\mathbf{0 . 1 0}$ & $96.12 \pm 0.67$ & $82.10 \pm 2.08$ & $90.15 \pm 1.56$ & $88.29 \pm 1.66$ \\
\hline $\mathbf{0 . 2 5}$ & $88.28 \pm 1.65$ & $97.29 \pm 0.57$ & $84.75 \pm 2.67$ & $85.29 \pm 2.76$ \\
\hline $\mathbf{0 . 5 0}$ & $80.98 \pm 3.17$ & $90.97 \pm 2.87$ & $87.46 \pm 3.00$ & $94.20 \pm 1.73$ \\
\hline $\mathbf{1 . 0 0}$ & $91.76 \pm 1.57$ & $97.10 \pm 1.66$ & $94.28 \pm 1.76$ & $97.16 \pm 1.69$ \\
\hline
\end{tabular}

${ }^{\mathrm{a}}$ Mean \pm Standard deviation

A very fast and simple cost-effective reversed-phase HPLC method coupled with modified QuEChERS has been developed for the determination of monocrotophos, deltamethrin, phosphamidon and dichlorvos insecticides (Fig. 3). The consistent recoveries found in cabbage samples ranging from 80.38 to $98.26 \%$ and in cauliflower, it was ranged from 80.98 to $97.29 \%$ for all the insecticides when both the samples were spiked at 0.05 , $0.10,0.25,0.50$ and $1.00 \mathrm{mg} / \mathrm{kg}$ levels. The present QuEChERS method is rather effective and provides the quickest, easy and cheap method as compared to other methods.

\section{Acknowledgments}

The authors are thankful to the Director, ICAR Research Complex for North Eastern
Hill region, Manipur Centre, Lamphelpat, India, for providing the necessary research facilities.

\section{References}

Chatterjee, S.S. 1986. Cole crops. Vegetable Crops in India. pp. 165-247. (Eds) Bose T K and Som M G. (Eds), Naya Prokash, Calcutta.

ENVIS Hub Manipur, 2015

Lal, O.P. 1975. A compendium of insect pest of vegetables in India. Bull. Ent. 16: 3156.

Sachan, J.N. and Gangwar, S.K. 1980. Vertical distribution of important pests of cole crops in Meghalaya as influenced by the environment factors. Indian J. Ent., 42: 414-421. 
Shovarani, N., Singh, R.K.I., Bandana, N., Singh, K.M., Anil, H., and Laishram, J.M. 2015. A survey report on application of pesticides on tomato (Lycopersicon esculantum) in Bishnupur district, a major commercial vegetable producing area in Manipur, India. Agrotechnol. 4(2):61.
Singh, M.K., Chandrasekaran, S., Singh, K.H.I., Singh, N.M., Singh, T.H.D., and Singh, N.R. 2010. Insecticide Residues in Market Samples of Brinjal in Imphal, Manipur, India. Asian J. Chem. 22(10): 7531-7534.

Status of Environment and Related Issues. http://manenvis.nic.in/Database/Pesticid eConsumption_3262.aspx.

\section{How to cite this article:}

Romila Akoijam, Arati Ningombam, Aruna Beemrote and Telem, R.S. 2018. RP-HPLC Method for Determination of Organophosphate and Synthetic Pyrethroids Insecticides. Int.J.Curr.Microbiol.App.Sci. 7(11): 3036-3041. doi: https://doi.org/10.20546/ijcmas.2018.711.348 